Çukurova Üniversitesi Mühendislik Mimarlık Fakültesi Dergisi, 31(ÖS 2), ss. ÖS 205-ÖS 209, Ekim 2016

Cukurova University Journal of the Faculty of Engineering and Architecture, 31(SI 2), pp. SI 205-SI 209, October 2016

\title{
Meyve Suyu Endüstrisi Atıksuyundan Mikrobiyal Biyopolimer Üretiminin Araştırılması
}

\author{
Ezgi BEZIRHAN ARIKAN"1, Havva Duygu ÖZSOY ${ }^{1}$, Abdullah EROL ${ }^{1}$, \\ Ayşe İSLAMOĞLU ${ }^{1}$, Derya Nida KAYA ${ }^{1}$, Sevinç ÇAKMAK ${ }^{1}$ \\ ${ }^{1}$ Mersin Üniversitesi, Mühendislik Fakültesi, Çevre Mühendisliği Bölümü, Mersin
}

Geliş tarihi: 10.08.2016 Kabul tarihi: 16.10 .2016

$\ddot{\mathbf{O} z}$

Biyoplastiklerin, geleneksel plastikler kadar yaygın kullanılmamasının en önemli nedeni yüksek üretim maliyetleridir. $\mathrm{Bu}$ nedenle son zamanlarda yapılan çalışmalar, yenilenebilir kaynaklar yerine atıklardan/atıksulardan biyoplastik üretimine odaklanmıştır. Ayrıca atıksudan biyoplastik üretiminde, saf kültür yerine aktif çamur gibi farklı mikrobiyal topluluklardan oluşan sistemlerin tercih edilmesi sterilizasyon işlemini ortadan kaldırdığından toplam üretim maliyetinde de azalmaya neden olmaktadır. $\mathrm{Bu}$ çalışmada, meyve suyu endüstrisi atıksuyunda bulunan karışı mikrobiyal biyokütle tarafindan biyopolimer üretimi araştırılmıştır. Bu amaçla, Mersin İli'nde bulunan bir meyve suyu endüstrisinin atıksuyu, laboratuvar ölçekli $5 \mathrm{~L}$ hacmindeki ardıșık kesikli reaktöre 10 günlük alıkonma süresi ve $120 \mathrm{~L} / \mathrm{sa}$ 'lik debi ile beslenmiştir. İlk bölme kısa bolluk, ikinci bölme uzun kıtlık ve üçüncü bölme çöktürme ünitesi olarak tasarlanan ardışık kesikli reaktörden 10 günlük alıkonma süresinin sonunda alınan çamur deneysel çalışmalarda kullanılmıştır. Çalışmada, $1 \mathrm{~g}$ çamurun kuru kütlesinden elde edilen biyopolimer \%19 olarak saptanmıștır. Ayrıca, kimyasal oksijen ihtiyacı (KOI) giderim veriminin \%77, AKM giderim verimin ise $\% 98$ olduğu tespit edilmiştir.

Anahtar Kelimeler: Aktif çamur, Ardışık kesikli reaktör, Biyoplastik, Biyopolimer, Meyve suyu endüstrisi atıksuyu

\section{Investigation of Microbial Biopolymer Production from Fruit Juice Industry}

\begin{abstract}
Bioplastics have not been used as much as traditional plastics because of their cost of production. Therefore, recent research has focused on producing bioplastics from wastes/wastewater instead of renewable resources. Moreover, the preference for systems consisting of different microbial communities such as activated sludge instead of pure culture decrease to total production cost. In this study, biopolymer production was investigated by mixed microbial biomass in the fruit juice wastewater. Wastewater of fruit juice industry located in Mersin was fed with a laboratory-scale $5 \mathrm{~L}$ sequencing batch reactor (SBR) with 10 day retention time and a flow rate of $120 \mathrm{~L} / \mathrm{h}$. SBR was designed three compartment; first feast phase, second famine phase and third settling unit. At the end of retention time, sludge taken from settling unit was used for experimental studies. $19 \%$ biopolymer was obtained from dry mass of $1 \mathrm{~g}$ sludge. COD removal yield was $77 \%$; SS removal yield was $98 \%$.
\end{abstract}

Keywords: Activated sludge, Bioplastic, Biopolymer, Fruit juice industry wastewater, Sequencing batch reactor

"Sorumlu yazar (Corresponding author): Ezgi BEZIRHAN ARIKAN, ezgibezirhan@gmail.com 


\section{GíRiş}

Plastikler, ahşap ve kağıt gibi malzemelere göre daha hafif ve ucuz olmaları nedeniyle endüstrideki tüketimi giderek artmaktadır. Ancak bu tüketimin getirdiği çevresel problemler, yasal baskılar ve plastiğin üretiminde kullanılan hammadde fiyatlarındaki dalgalanmalar plastik üretiminde alternatif arayışları gündeme getirmiştir. Son yıllarda geliştirilen alternatif malzemelerden biri de biyoplastiklerdir.

Biyoplastikler genellikle, şeker, misır ve patates gibi $[1,2]$ protein, lipit ve polisakkaritleri içeren yenilenebilir kaynaklardan [3,4] ya da bazı mikroorganizmalardan, alglerden ve mantarlardan üretilebilen [5,6] malzemelerdir.

Farklı türde mikroorganizmaların azotça fakir ve karbonca zengin atıksularda polihidroksi alkanat (PHA), polihidroksi bütirat (PHB) gibi biyopolimer türlerini üretebildikleri bilinmektedir. PHA'lar doğada bakterilerin şeker ya da yağları fermente etmesi ile üretilen düz zincirli poliesterlerdir. Bunlar, bakteriler tarafindan karbon ve enerji depolamak için üretilmektedirler [7]. PHA'lar, ilaç ve hormonların yavaş salınımı için kullanılan kapsüller, kemik plakaları, sentetik kemik üretimi materyalleri, ameliyat iplikleri gibi medikal uygulamalarda ve boya üretimi, yalıtım malzemesi üretimi gibi endüstrilerde ham madde olarak kullanılabilmektedir. Ayrıca herbisit ve insektisitlerin yavaş salınımları için tarımda, aroma ve kokunun zamanla ortaya çıkması amacıyla gıda endüstrisinde de kullanılabilmektedir.

Yıllardır gündemden düşmeyen açlık problemleri nedeniyle biyoplastik üretiminde gida hammaddelerinin kullanılması üreticiler ve tüketiciler tarafindan büyük bir çelişki olarak görülmüştür. Aynı zamanda gıda hammaddelerinden biyoplastiğin üretim maliyetini artırdığı da düşünülmektedir. Üretim maliyetinin yüksek olması biyoplastiklerin geleneksel plastikler kadar yaygın kullanılmasını da engellemektedir. Çünkü geleneksel plastiklerin 1 kg'1 yaklaşık 1,2 $€$ iken, biyoplastiklerin 1 kilogramı 3 ile $5 €$ arasında değişmektedir [8].
Bu nedenlerle, son zamanlarda yapılan araştırmalar biyoplastiklerin üretim maliyetlerinin azaltılması üzerine odaklanmıştır. Ayrıca, biyoplastiklerin üretimi için (1) daha ucuz subsratların kullanımının, (2) yeni fermantatif teknolojik yöntemlerin [9,10], (3) biyoplastiğin geri kazanım ve saflaştırma yöntemlerinin [11] ve (4) sterilizasyon olmaksızın karışık kültürler ile üretim yöntemlerinin araştırılması gerekmektedir [12].

Çukurova Bölgesinde bulunan Mersin İli Türkiye'nin meyve ve sebze üretiminin ve işlenmesinin merkezlerinden biridir. Seracılık faaliyetlerinin geliştiği bu bölge, iklimi nedeni ile sebze ve meyveleri her sezonda yetiştirilebilme şansına sahiptir. Özellikle sebze ve meyve işlemesi sırasında açığa çıkan atık sular ve posa, yüksek karbon içeriği nedeni ile PHA ya da özellikle PHB türevleri üretebilen mikroorganizmaların çok düşük maliyet ile yetiştirilebilmesi için oldukça uygun bir substrat olarak görülmektedir. Çünkü meyve suyu üretim endüstrisi atık suları organik asitler ve mono/disakkaritler gibi düşük molekül ağırlıklı ve kolay parçalanabilir organik içeriği yüksek atık sular olarak bilinmektedirler.

Meyve işleme endüstrilerinde oluşan atıksuların arıtılmadan doğaya deşarj edilmesi, bir dizi çevresel probleme neden olabilir. $\mathrm{Bu}$ nedenle, yasal düzenlemelerin baskısı altında fiziksel, kimyasal, biyolojik arıtım tekniklerinden bir veya birkaçı kullanılarak arıtımları gerçekleştirilir. Arıtım maliyetinin yüksek ya da düşük olması atığın karakterine bağlı olarak değişse de bu maliyet işletme sahiplerine ek yük getirdiğinden, ürünün satış fiyatına yansıtılmakta ve ürünün tüketiciye yüksek fiyattan ulaşmasına neden olmaktadir.

Aktif çamur gibi karışık mikrobiyal biyokütle içeren sistemlerin sterilizasyon gerektirmemeleri ve ucuz/karışık türde besin kaynağ 1 (subsrat) içeren atıksuyun kullanılması ile biyoplastik üretim maliyetini azaltılacağı öngörülmektedir. $\mathrm{Bu}$ nedenlerle bu çalışmanın amacı, meyve suyu endüstrisi atıksuyunun giderimini sağlarken, aynı zamanda aktif çamur prosesi ile bu atıksudan biyopolimer üretimini araştırmaktır. 


\section{MATERYAL VE METOT}

\subsection{Materyal}

Çalışmada biyopolimer üretimi için gereken mikrobiyal biyokütlenin eldesinde meyve suyu endüstrisi atık suyu kullanılmıştır. Meyve suyu endüstrisi atıksuyu Mersin İlinde bulunan Anadolu Etap Tarım ve Gıda Ürünleri San. ve Tic. AŞ'den temin edilmiştir. Çalışmada kullanılan aktif çamur ise aynı işletmenin atıksu arıtma tesisinin havalandırma havuzundan temin edilmiştir. Bütün çalışmalar Mersin Üniversitesi, Mühendislik Fakültesi, Çevre Mühendisliği su ve atıksu laboratuvarı ile biyoteknoloji laboratuvarında gerçekleştirilmiştir.

\subsection{Metod}

\subsubsection{Atıksu Karakterizasyonu}

Meyve suyu endüstrisi atı suyunun karakterizasyonu amacı ile $\mathrm{pH}$, iletkenlik, sıcaklık, Askıda katı madde (AKM) ve Kimyasal Oksijen İhtiyacı (KOİ) analizleri standart metotlara göre gerçekleştirilmiştir [13].

\subsubsection{Ardışık Kesikli Reaktör Çalışmaları}

Çalışmalar, laboratuvar ölçekli üç kademeden oluşan 5L hacimli reaktörlerde gerçekleştirilmiştir. İlk kademe mikroorganizmaların biyokütle artışının gerçekleşmesi için, atıksu 120 L/sa'lik debi ve 10 gün'lük alıkonma süresi ile beslenmiştir. Reaktörün ikinci kademesi, birinci kademeden gelen azot oranı düşük atıksu ile beslenmiştir. Sistemin her iki kademesi de yeterli çözünmüş oksijenin sağlanması amacıyla havalandırılmış ve tam karışım sağlanmıştır. Ayrıca reaktörün her iki kademesine de toplamda $875 \mathrm{~mL}$ olmak üzere aktif çamur ilavesi yapılmıştır. Alıkonma süresi içerisinde 1-2-3-5-8-9 ve 10. günlerde meyve suyu atıksuyunda arıtımın gerçekleştirilip gerçekleştirilmediğinin tespiti amacı ile KOİ, AKM, pH ve iletkenlik parametreleri de belirlenmiştir.
Alıkonma süresinin sonunda, biyokütlenin hasatı çöktürme amaçlı tasarlanmış olan reaktörün üçüncü kademesinden çöktürülerek gerçekleştirilmiştir. Hasat edilen biyokütle, biyopolimer ekstraksiyon çalışmalarında kullanılmıştır.

\subsubsection{Biyopolimer Ekstraksiyon Analizleri}

Hasat edilen biyokütle santrifüj edilerek (6000 rpm, 20 dakika) sıvı fazdan ayrılmıştır. Santrifüj sonrası toplanan biyokütle tartıldıktan (yaş ağırlık) sonra $80^{\circ} \mathrm{C}$ 'de 24 saat süre ile etüvde kurutularak sabit tartıma getirilmiş ve kuru kütle saptanmıştır [14].

Ardından elde edilen kuru kütleden biyopolimerin gravimetrik tayini [15] gerçekleştirilmiştir; $1 \mathrm{~g}$ kuru kütle hassas terazide tartılarak $50 \mathrm{~mL}$ 'lik santrifüj tüpüne konmuş ardından üzerine $12,5 \mathrm{~mL}$ sodyum hipoklorit ve $12,5 \mathrm{~mL}$ kloroform eklenerek ve vortekslenmiştir. Vortekslenen numune $30^{\circ} \mathrm{C}$ ' de su banyosunda $90 \mathrm{dk}$ bekletilmiş, 90 dk'nın sonunda 4000 rpm'de 15 dk santrifüjlenmiştir. Sanrtifüj sonunda oluşan 3 tabakadan (Şekil 1) en alt faz pipetle dikkatlice alınarak bir tüpe konulmuștur. $7 / 3$ oranında hazırlanan metanol/su karışımından 1,25 mL bu fazın üstüne eklenmiş ve filtre edilmiştir. Tüpün ağzı açık kalacak şekilde 48 saat (çözücülerin uçurulması için) çeker ocakta bekletilmiş, 48 saatin sonunda elde edilen peletlerin tartımı yapılmıştır. $1 \mathrm{~g}$ kuru kütleden elde edilen biyopolimer miktarı yüzde olarak sonuçlandırılmıştır.

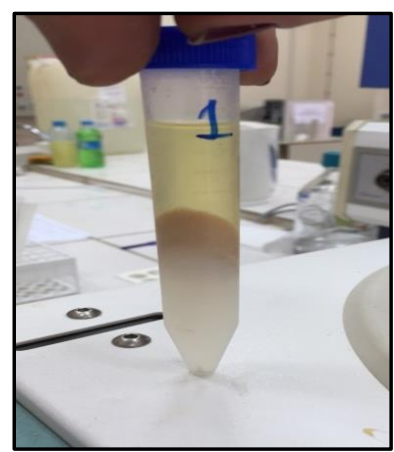

Şekil 1. Biyopolimerin gravimetrik tayini sırasında oluşan üç faz 


\section{BULGULAR VE TARTIŞMA}

\subsection{Atıksu Karakterizasyon Sonuçları}

Standart metotlara göre belirlenen meyve suyu endüstrisi giriş atık suyunun karakterizasyon sonuçları Çizelge 1'de gösterilmektedir.

Çizelge 1. Meyve işleme endüstrisi giriş atıksuyu parametreleri

\begin{tabular}{|l|l|}
\hline Parametreler & Değer \\
\hline AKM $(\mathrm{mg} / \mathrm{L})$ & 7554 \\
\hline KOİ $(\mathrm{mg} / \mathrm{L})$ & 7191,4 \\
\hline $\mathrm{pH}$ & 6,24 \\
\hline İletkenlik $(\mu \mathrm{s} / \mathrm{cm})$ & 272 \\
\hline
\end{tabular}

\subsection{Ardışık Kesikli Reaktör Çalışmaları}

Üç kademeli 5L'lik reaktörün alıkonma süresi içerisinde 1-2-3-5-8-9 ve 10. günlerinde meyve suyu atıksuyunda arıtımın gerçekleştirilip gerçekleştirilmediğinin tespiti amacı ile gerçekleştirilen KOİ, AKM, pH ve iletkenlik analizlerinin sonuçları Çizelge 2'de gösterilmektedir.

Çizelge 2. Meyve işleme endüstrisi giriş atıksuyu parametreleri

\begin{tabular}{|l|c|c|c|c|c|c|c|}
\hline Parametreler & 1. gün & 2. gün & 3. gün & 5. gün & 8. gün & 9. gün & 10. gün \\
\hline $\mathrm{AKM}(\mathrm{mg} / \mathrm{L})$ & 7250 & 426,6 & 43,93 & 1243 & 436 & 1443 & 130 \\
\hline KOİ $(\mathrm{mg} / \mathrm{L})$ & 464,2 & 509,7 & 1081,1 & 925,1 & 1124 & 1412,6 & 1649,4 \\
\hline $\mathrm{pH}$ & 8,8 & 8,6 & 6,94 & 7,62 & 6,55 & 7,26 & 7,35 \\
\hline $\begin{array}{l}\text { îletkenlik } \\
(\mu \mathrm{s} / \mathrm{cm})\end{array}$ & 315 & 391 & 262 & 351 & 362 & 297 & 265 \\
\hline
\end{tabular}

KOİ ve AKM parametrelerinin zamana bağlı değişimleri ise Şekil 2 ve Şekil 3'de gösterilmektedir.

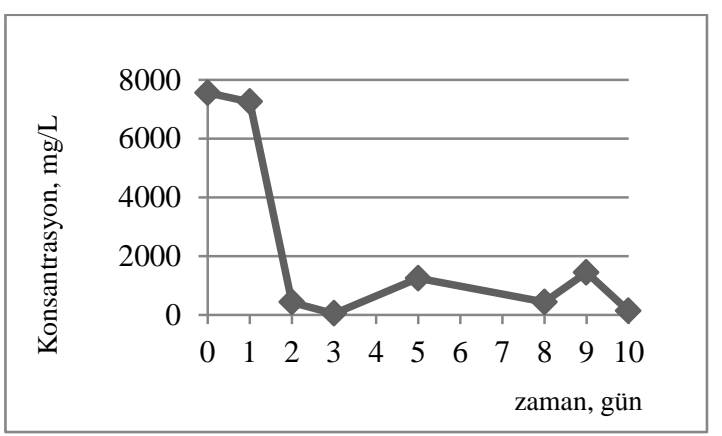

Şekil 2. AKM'nin zamana bağlı değişim grafiği

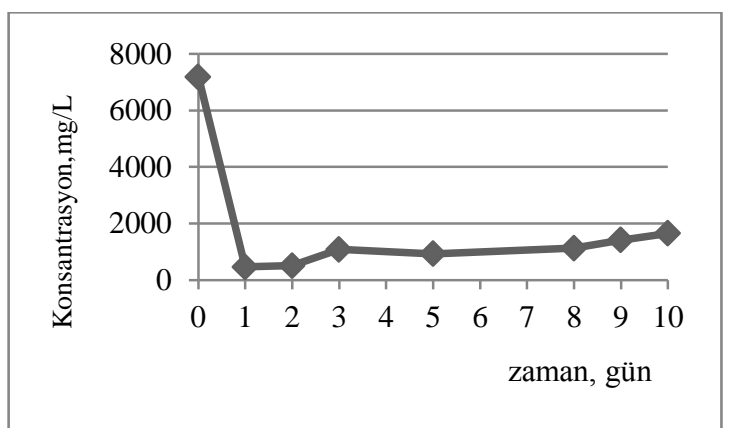

Şekil 3. KOİ'nin zamana bağlı değişim grafiği

Analiz sonuçlarına göre reaktöre yükleme yapıldıktan 1 gün sonra KOİ gideriminde $\% 93$ oranında, alıkonma süresi sonunda ise $\% 77$ oranında giderim belirlenmiştir. Reaktöre yükleme yapıldıktan 2 gün sonra ise AKM gideriminde $\% 94$, al1konma süresinin sonunda ise $\% 98$ verim elde edildiği tespit edilmiștir. AKM ve KOİ parametrelerinin zamanla değişiklik göstermesi atıksudaki biyokütlenin zamanla artışı ve azalışına bağlanmaktadır.

\subsection{Biyopolimer Ekstraksiyon Analizi Sonuçları}

Reaktörden hasat edilen biyokütlenin kuru kütlesine uygulanan gravimetrik biyopolimer tayini sonucunda $1 \mathrm{~g}$ kuru biyokütleden 0,19 g biyopolimer elde edilmiştir. Buna göre meyve suyu endüstrisi atıksuyu ile beslenen tam karışımlı reaktörde biyopolimer elde etme verimi \%19 olarak tespit edilmiştir.

\section{SONUÇ}

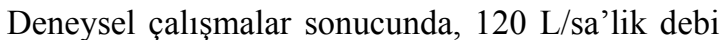
ile tam karışımlı ardışık kesikli reaktöre beslenen meyve suyu endüstrisi atıksuyunun 10 gün'lük alıkonma süresi sonunda $\% 77$ oranında KOİ giderimi, $\% 98$ oranında ise AKM giderimi sağlanmış, \%19 oranında da biyopolimer elde edildiği tespit edilmiştir. Alıkonma süresinin kısaltılması ile arıtım veriminin de artacağı düşünülmektedir. Biyopolimer ekstraksiyon yöntemlerinin biyopolimer eldesinde önemli rol oynadığı düşünülerek, çalışmanın farklı yöntemlerle yinelenmesi ile elde edilen 
biyopolimer yüzdesinin artırılabileceği düşünülmektedir. Dinamik şartlarda zenginleştirilen biyokütlenin daha yüksek organik yüklemelere maruz bırakılması ile daha fazla biyopolimer depolayacağı da düşünülmektedir. Ayrica çalışma sonunda elde edilen biyopolimer türünün (PHA, PHB vb.) belirlenmesi de önerilmektedir.

\section{KAYNAKLAR}

1. Sarasa, J., Gracia, J.M., Javierre, C., 2008. Study of the Biodisintegration of a Bioplastic Material Waste, Bioresource Technology, 100, 3764-3768.

2. Karana, E., 2012. Characterization of 'Natural' and 'High-quality' Materials to Improve Perception of Bioplastics, Journal of Cleaner Production, 37, 316-325.

3. Averous, L., 2004. Biodegradable Multiphase Systems Based on Plasticized Starch: a Review, J. Macromol. Sci. C Polym. Rev., 44, 231-274.

4. Siracusa V., Rocculi P., Romani S., Dalla Rosa M., 2008. Biodegradable Polymers for Food Packaging: a Review, Trends Food Science Technology, 19, 634-643.

5. Luengo, J.M., Garcia, B., Sandoval, A., Naharro, G., Olivera, E.R., 2003. Bioplastics from Microorganisms, Current Opinion in Microbiology, 6, 251-260.

6. Özdemir, N., Erkmen, J., 2013. Yenilenebilir Biyoplastik Üretiminde Alglerin Kullanımı, Karadeniz Fen Bilimleri Dergisi/The Black Sea Journal of Sciences, .3(8), 89-104.

7. Başak B., İnce O., 2011. Azot Kisıtlı Atıksulardan Biyoplastik Üretimi için Yeni Bir Aktif Çamur Prosesi, İTÜ Dergisi, Su Kirliliği ve Kontrolü, 21(1), 45-54.

8. Song, J.H., Murphy, R., Narayan, J.R., Davies, G.B.H., 2009. Biodegradable and Compostable Alternatives to Conventional Plastics, Phil. Trans. R. Soc. 364, 2127-2139.

9. Choi, J., Lee, S.Y., 1999. Efficient and Economical Recovery of Poly (3hydroxybutyrate) from Recombinant Escherichia coli by Simple Digestion with
Chemicals, Biotechnol. Bioeng., 62(5), 546-553.

10. Lee, S.Y., 1996. Plastic Bacteria? Progress and Prospects for Polyhydroxyalcanoate Production in Bacteria, Trends Biotechnol., 14(11), 431-438.

11. Shang, L., Jiang, M., Chang, H.N., 2003. Poly (3-Hydroxybutyrate) Synthesis in Fedbatch Culture of Ralstonia Eutropha with Phosphate Limitation under Different Glucose Concentrations, Biotechnol. Lett., 25, 1415-1419.

12. Bosco, F., Chiampo, F., 2010. Production of Polyhydroxyalcanoates (PHAs) using Milk Whey and Dairy Wastewater Activated Sludge Production of Bioplastics using Dairy Residues, Journal of Bioscience and Bioengineering 109(4), 418-421.

13. APHA, AWWA, WPCF., 2005. Standard Methods for the Examination of Water and Wastewater, $21^{\text {st }}$ Ed., Washington D.C.

14. Mitra, D., Rasmussen, M.L., Chand, P., Chintareddy, V.R., Yao, L., Grewell, D., Verkade, J., Wang, T., van Leeuwen, J.H., 2012. Value-added Oil and Animal Feed Production from Corn-ethanol Stillage using the Oleaginous Fungus Mucor Circinelloides, Biores. Technol., 107, 368-375.

15. Wang, B., Sharma-Shivappa, R.R., Olson, J.W., Khan, S.A., 2013. Production of Polyhydroxybutyrate (PHB) by Alcaligenes Latus using Sugarbeet Juice, Industrial Crops and Products, 43, 802-811. 
